\title{
CHẨN ĐOÁN VÀ ĐIỀU TRI U CUỘN CẢNH VÙNG ĐẦU CỔ
}

\section{Đoàn Quốc Hung**, Phạm Tuấn Cảnh*,Chư Vân Khánh**}

\section{TÓM TẮT}

U cuộn cảnh (glomus tumors) vùng đầu cổ là khối u hiếm gặp, tiến triển chậm, giàu mạch máu, thuộc nhóm các u cận hạch (paragangliomas), có thể xuất hiện ở nhiều vị trí khác nhau. Nghiên cứu của chúng tôi tìm hiểu về lâm sàng, chẩn đoán hình ảnh, đối chiếu chẩn đoán hình ảnh với tổn thương trong mổ để rút ra kinh nghiệm cho chẩn đoán và chỉ định điều trị bệnh lý này. Đối tượng nghiên cứu bao gồm 23 bệnh nhân $(\mathrm{BN})$ với $24 \mathrm{u}$ được chẩn đoán $u$ cuộn cảnh, điều trị phẫu thuật tại khoa Phẫu thuật Tim mạch Bệnh viện Việt Đức, Bệnh viện Tai Mũi Họng trung ương, Bệnh viện Đại Học Y Hà Nội từ tháng 1 năm 2008 đến tháng 9 năm 2016. Chẩn đoán xác định dựa vào lâm sàng, cận lâm sàng và khẳng định bằng kết quả giải phẫu bệnh. Trong 24 khối u có $17 \mathrm{u}$ tiểu thể cảnh, $2 \mathrm{u}$ tiểu thể thần kinh phế vị và $5 \mathrm{u}$ cuộn nhĩ. Tất cả $\mathrm{BN}$ đều cắt toàn bộ $\mathrm{u}$, trong đó $2 \mathrm{BN}$ tái lập tuần hoàn động mạch cảnh trong, $2 \mathrm{BN}$ thắt động mạch cảnh ngoài và $4 \mathrm{BN}$ thắt đoạn thần kinh. Kết luận: $U$ cuộn cảnh vùng đầu cổ là bệnh hiếm gặp, chẩn đoán xác định chủ yếu dựa vào chẩn đoán hình ảnh. Điều trị chủ yếu là phẫu thuật lấy trọn khối $u$, ngoài ra cần xem xét các phương pháp điều trị khác như xạ trị, phẫu thuật bằng dao gamma nhằm chọn hướng giải quyết hợp lý nhất cho mỗi BN cụ thể.

SUMMARY: Glomus tumors (paragangliomas) of the head and neck are rare, slowly progressive, rich in blood vessels, tumors in the group of access nodes (paragangliomas), can appear in many different positions. Research on clinical diagnosis, medical imaging comparing with surgical lesions in order to withdraw experience to diagnose and treat this rare pathology. Study subjects included 23 patients (24 tumors) with glomus tumors, surgical treatment at
Cardiovascular surgery-Viet Duc Hospital, ENT Central Hospital, Hanoi Medical University Hospital from january 2008 to september 2016. The definitive diagnosis is based on clinical, paraclinical and confirmed by pathology results. In 24 tumors with 17 carotid body tumors, 2 glomus vagales and 5 glomus tympanicums. All cases were surgically excised, including 2 cases of re-establishing circulation of the internal carotid artery, 2 cases of external carotid artery ligation and 4 cases of nerve ligation clip. Conclusion: Glomus tumors of the head and neck are rare, definitive diagnosis relies on diagnostic imaging. Treatment is total tumorectomy, in addition to consideration of other therapies such as radiation therapy, gamma knife surgery in order to select the most appropriate solutions for each specific case. $^{7}$

\section{I. ĐẶT VẤN ĐỀ}

U cuộn cảnh (glomus tumor) vùng đầu cổ là khối u hiếm gặp, tiến triển chậm, giàu mạch máu, thuộc nhóm các u cận hạch (paragangliomas) có thể xuất hiện ở nhiều vị trí khác nhau như: tiểu thể cảnh (carotid body), tiểu thể thần kinh phế vị (glomus vagale), cuộn nhĩ (glomus tympanicum)...Trong đó $\mathrm{u}$ tiểu thể cảnh hay gặp nhất (chiếm khoảng $65 \%$ ) [1]. Ở vùng đầu cổ tỷ lệ gặp u tiểu thể cảnh là khoảng 1/300.000 người mỗi năm. Chúng là khối u phổ biến nhất của nhóm khối u cận hạch ngoài thượng thận [2]. U cuộn cảnh đầu cổ hay gặp ở nữ giới, tỷ lệ nam:nữ là xấp xỉ 1:1,5-4 tùy nghiên cứu [3],[4]. Tuổi khởi phát thường là từ $30-60$ tuổi [4], đa số là xuất hiện một bên, bên trái

\footnotetext{
* Khoa Phẫu thuật Tim mạch và Lò̀ng ngục BV HN Việt Đúc ** Bệnh Viện Phố Nối-Hưng Yên

Nguời chịu trách nhiệm khoa học: PGS.TS. Đoàn Quốc Hung Ngày nhận bài: 01/08/2017 - Ngày Cho Phép Đăng: 07/08/2017 Phản Biện Khoa hoc: PGS.TS. Đặng Ngoc Hùng GS.TS. Lê Ngoc Thành
} 
chiếm ưu thế hơn so với bên phải. Yếu tố gia đình cũng được ghi nhận đặc biệt ở nhóm khối u cuộn cảnh hai bên [6]. Chẩn đoán không khó bằng lâm sàng, cận lâm sàng (đặc biệt là chẩn đoán hình ảnh), biến chứng của u là chèn ép các tạng lân cận (mạch máu, thần kinh) và ác tính hóa. Điều trị chủ yếu là mổ lấy trọn khối u [4]. Nút mạch trước rồi phẫu thuật sau sẽ làm giảm được nguy cơ chảy máu [5]. Những năm gần đây biện pháp xạ trị hoặc phẫu thuật thuật bằng gamma-knife cũng cho những kết quả ấn tượng về khả năng kiểm soát khối u, hạn chế các biến chứng có liên quan tới dây thần kinh sọ [7]. Tại Việt Nam hầu như chưa có nhiều nghiên cứu về bệnh lý này, nên việc thực hiện đề tài đánh giá về chẩn đoán và điều trị u cuộn cảnh vùng đầu cổ là cần thiết, đóng góp với y văn thế giới

\section{II.VÀI NÉT VỀ DANH PHÁP BỆNH HỌC}

U cuộn cảnh có nguồn gốc từ các tế bào chính của các mô cận hạch cấu tạo nên cuộn cảnh. Do các cuộn cảnh có bản chất là các tế bào thần kinh nội tiết, có chức năng điều tiết tuần hoàn vùng đầu mặt cổ chủ yếu thông qua các receptor nhạy cảm hóa học (chemoreceptor), u cuộn cảnh còn có tên khác là chemodectoma.

Theo giải phẫu đại thể, $u$ cuộn cảnh vùng đầu cổ được xếp thành 2 nhóm: u cuộn cảnh thái dương và u cuộn cảnh vùng cổ. $U$ cuộn cảnh thái dương gồm: u cuộn nhĩ (glomus tympanicum tumor) và u cuộn tĩnh mạch (glomus jugulare tumor). Trong trường hợp khối u phát triển rộng xâm lấn cả tai giữa được gọi là u cuộn cảnh hòm nhĩ (jugulotympanic glomus tumors). U cuộn cảnh vùng cổ gồm: $\mathrm{U}$ tiểu thể cảnh (carotid body tumor) có nguồn gốc từ các tiểu thể cảnh và u tiểu thể thần kinh phế vị (glomus vagale tumor) có nguồn gốc từ các cuộn cảnh dọc theo dây X. Tuy nhiên về mặt cấu trúc vi thể do không thể phân biệt được sự khác biệt giữa u cuộn cảnh với các khối u tủy thượng thận hoặc các khối u cận hạch ở các vị trí khác của cơ thể nên WHO (2004) xếp u vào nhóm các khối u cận hạch ngoài thượng thận (extra-adrenal paraganglioma). Trong phạm vi bài này để tiện cho việc theo dõi tôi vẫn sử dụng danh pháp cũ là khối u cuộn cảnh.

Các khối u cận hạch nhìn chung đều có hai loại tế bào: tế bào chính và tế bào đệm, trong đó các tế bào chứa các hạt dự trữ catecholamines. Tuy nhiên chỉ dưới $5 \%$ số u cuộn cảnh vùng đầu cổ có khả năng tiết ra norepinephrine [7]. Trên tiêu bản mô học, tế bào chính xếp thành đám và được bao bọc bởi các tế bào đệm, bên trong tổ chức mô đệm giàu mạch máu. U cuộn cảnh ác tính tỉ lệ khoảng 5$30 \%$. Việc chẩn đoán tính chất ác tính không phụ thuộc vào tổ chức mô học mà phụ thuộc vào có hay không có tổn thương di căn xa [8].

\section{III. ĐỐI TƯợNG VÀ PHƯƠNG PHÁP NGHIÊN CÚU}

- Gồm các $\mathrm{BN}$ chẩn đoán sau mổ là u cuộn cảnh vùng đầu cổ điều trị tại $\mathrm{BV}$ Việt Đức, $\mathrm{BV}$ Tai mũi họng trung ương, BV Đại học Y Hà nội từ $1 / 2008$ tới 9/2016.

- Thiết kế nghiên cứu: Nghiên cứu hồi cứu, mô tả từng ca có can thiệp.

- Cỡ mẫu: Sử dụng phương pháp chọn mẫu thuận tiện.

- Thu thập và xử lý số liệu bằng phương pháp thống kê toán học y học với chương trình SPSS 16.0.

\section{KẾT QUẢ NGHIÊN CÚU}

4.1.Đặc điểm chung: có 23 bệnh nhân (BN) với 24 khối u cuộn cảnh được phẫu thuật từ 1/2008 tới 9/2016 đủ tiêu chuẩn nghiên cứu

-Tuổi, giới: BN gồm 17 nữ, 6 nam, tuổi thấp nhất 20 tuổi, cao nhất 61 tuổi, trung bình là 41,7 tuổi, lứa tuổi từ $30-60$ tuổi có $16 / 23 \mathrm{BN}$ $(69,5 \%)$.

-Vị trí khối u: Đa số các khối u xuất hiện một bên với 22/23 BN (95,7\%). Bên trái chiếm ưu thế hơn so với bên phải (Bên trái $52,2 \%$, bên phải 43,5\%).

-Phân loại: Trong 24 khối u có $17 \mathrm{u}$ tiểu thể cảnh, $2 \mathrm{u}$ tiểu thể thần kinh phế vị và $5 \mathrm{u}$ cuộn nhĩ. 


\section{2.Đặc điểm nhóm BN u cuộn cảnh vùng cổ (18 BN với 19 u)}

Bảng 4.1: Triệu chứng lâm sàng u cuộn cảnh vùng cổ (18 BN với 19 u)

\begin{tabular}{|l|c|c|}
\hline \multicolumn{1}{|c|}{ Lý do đi khám bệnh } & Số bệnh nhân & $\%$ \\
\hline Khối vùng cổ/ góc hàm & 18 & 94,4 \\
\hline Nuốt vướng, nuốt khó & 4 & 22,2 \\
\hline Đau nửa đầu & 2 & 11,1 \\
\hline Sụp mi cùng bên & 1 & 5,6 \\
\hline Tăng huyết áp & 2 & 11,1 \\
\hline Đã mổ ở tuyến trước* & 6 & 33,3 \\
\hline
\end{tabular}

*Đã mổ ở tuyến trước, đều không có giấy tờ, $\mathrm{BN}$ mô tả nhớ lại chẩn đoán là hạch, hay u máu, hay u tuyến dưới hàm và đều không có kết quả GPB.

-Đặc điểm khối u: Khối u vùng cổ/ góc hàm còn di động có 12/19 u (63,2\%). Khối u vùng cổ/ góc hàm gây biến dạng cổ, ít hoặc không di động có 7/19 u (36,8\%).

Bảng 4.2: Các phương pháp chẩn đoán hình ảnh u cuộn cảnh vùng cổ ( $\mathrm{n}=18 \mathrm{BN})$

\begin{tabular}{|l|c|c|}
\hline \multicolumn{1}{|c|}{ Loại thăm dò } & Số bệnh nhân & $\%$ \\
\hline Siêu âm Doppler* & 18 & 100 \\
\hline Cắt lớp vi tính & 7 & 38,9 \\
\hline Cắt lớp vi tính đa dãy MSCT dựng hình ĐM** & 11 & 55,6 \\
\hline Chụp động mạch cảnh** & 13 & 72,2 \\
\hline Cộng hưởng từ & 6 & 33,3 \\
\hline
\end{tabular}

*100\% khối u tăng sinh mạch trên siêu âm Doppler.

**8/11 BN (72,7\%) trên chụp MSCT và 13/13 BN (100\%) trên chụp ĐM cảnh có

hình ảnh khối u tăng sinh mạch; có $9 / 11 \mathrm{BN}(81,8 \%)$ và $11 / 13 \mathrm{BN}(84,6 \%)$ có hình ảnh đẩy roãng rộng chạc ba ĐM cảnh.

- Phương pháp điều trị và kết quả

Bảng 4.3: Can thiệp nút mạch trước mổ $(\mathrm{n}=19 \mathrm{u})$

\begin{tabular}{|c|c|c|c|}
\hline \multicolumn{2}{|c|}{ Can thiệp nút mạch $(\mathrm{n}=19)$} & Số u & $\%$ \\
\hline \multicolumn{2}{|c|}{ Có nút mạch } & 14 & 73,7 \\
\hline \multicolumn{2}{|c|}{ Không nút mạch } & 5 & 26,3 \\
\hline \multirow{3}{*}{$\begin{array}{c}\text { Số mạch được nút } \\
(n=14)\end{array}$} & Nút 1 nhánh & 3 & 21,4 \\
\hline & Nút nhiều nhánh & 7 & 50 \\
\hline & Không mô tả rõ & 4 & 28,6 \\
\hline
\end{tabular}

Trong nhóm có nút mạch có truyền máu 3/14 (21,4\%), trong nhóm không nút mạch có truyền máu 2/5 (40\%). 
Bảng 4.4: Phẫu thuật $(\mathrm{n}=19$ u)

\begin{tabular}{|l|c|c|}
\hline \multicolumn{1}{|c|}{ Phẫu thuật } & Số u & $\%$ \\
\hline Mổ có chuẩn bị & 19 & 100 \\
\hline Cắt toàn bộ u & 19 & 100 \\
\hline Tái lập tuần hoàn ĐM cảnh trong & 2 & 10,5 \\
\hline Thắt ĐM cảnh ngoài & 2 & 10,5 \\
\hline Thắt đoạn thần kinh & 4 & 21 \\
\hline
\end{tabular}

Có $1 \mathrm{BN}$ u cuộn cảnh 2 bên sau mổ: Siêu âm tắc ĐM cảnh ngoài có $3 / 18$ (16,7\%); khàn tiếng, nói khó 4/18 (22,2\%); rối loạn nuốt (phải mở thông dạ dày) 1/18 (5,6\%); Sụp mi (có hồi phục) 1/18 $(5,6 \%)$. Không có $\mathrm{BN}$ nào bị chảy máu sau mổ hoặc tai biến thần kinh trung ương.

Bảng 4.5: Đối chiếu kết quả siêu âm Doppler với tổn thương trong mổ (n=19 u)

\begin{tabular}{|l|c|c|c|c|}
\hline \multirow{2}{*}{ KQ siêu ẫu thuật } & \multicolumn{2}{c|}{ U tiểu thể cảnh } & \multicolumn{2}{c|}{ U tiểu thể thần kinh phế vị } \\
\cline { 2 - 5 } & Số u & $\%$ & Số u & $\%$ \\
\hline Hình ảnh nghĩ tới u cuộn cảnh & 13 & 76,5 & 2 & 100 \\
\hline Hình ảnh nghĩ tới tồn thương khác & 4 & 23,5 & 0 & - \\
\hline \multicolumn{1}{|c|}{ Tổng } & 17 & 100 & 2 & 100 \\
\hline
\end{tabular}

Bảng 4.6: Đối chiếu kết quả CLVT/MSCT/MRI với tổn thương trong mổ $(\mathrm{n}=18)$

\begin{tabular}{|c|c|c|c|c|}
\hline \multirow{2}{*}{$\begin{array}{ll}\text { CLVT/MSCT/MRI } & \text { Phẫu thuật }\end{array}$} & \multicolumn{2}{|c|}{ U tiểu thể cảnh } & \multicolumn{2}{|c|}{ U tiểu thể thần kinh phế vị } \\
\hline & Số u & $\%$ & Số u & $\%$ \\
\hline Hình ảnh nghĩ đến u cuộn cảnh & 14 & 87,5 & 2 & 100 \\
\hline Hình ảnh nghĩ tới tổn thương khác & 2 & 12,5 & 0 & - \\
\hline Tổng & 16 & 100 & 2 & 100 \\
\hline
\end{tabular}

GPB: 17/19 u (89,5\%) paraganglioma, 2/19 u (10,5\%) schwannoma.

4.3. Đặc điểm nhóm BN U cuộn cảnh vùng thái duơng $(n=5 \mathrm{BN})$

- Triệu chứng lâm sàng và lý do đi khám bệnh: Cả $5 \mathrm{BN}$ đều có triệu chứng ù tai theo nhịp mạch, chỉ có $2 / 5 \mathrm{BN}$ có triệu chứng nghe kém, các triệu chứng về tổn thương thần kinh, chóng mặt... không gặp.

- Đặc điểm u lúc khám lâm sàng: 4/5 BN nội soi tai thấy hình ảnh màng nhĩ bị xung huyết màu hồng nhạt, có $1 / 5 \mathrm{BN}$ nội soi thấy khối u đã bắt đầu vượt ra màng nhĩ lan ra ống tai ngoài.

- Các loại thăm dò: trong nghiên cứu cả $5 \mathrm{BN}$ đều được đo thính lực đồ và chụp CLVT xương thái dương, chụp cộng hưởng từ $1 / 5 \mathrm{BN}$, chụp phim Schuller có $1 / 5 \mathrm{BN}$, đo nhĩ lượng có $2 / 5$ $\mathrm{BN}$, không $\mathrm{BN}$ nào chụp chụp ĐM.

- Đặc điểm trên CLVT xương thái dương: hình ảnh tổ chức mờ khu trú trong hòm nhĩ, ranh giới rõ với vịnh tĩnh mạch cảnh và động mạch cảnh đoạn trong xương đá, chuỗi xương con hình dạng và vị trí bình thường. $1 \mathrm{BN}$ chụp cộng hưởng từ kết quả TD u cận hạch (paraganglioma) thể khu trú trong hòm tai.

- GPB: cả 5 BN đều là glomus tumor

V. BÀN LUẬN

5.1. Dịch tê học: $23 \mathrm{BN}$ của chúng tôi gồm 17 nữ và 6 nam. Theo một số tác giả u cuộn cảnh gặp ở nữ nhiều hơn ở nam [2],[4], thường gặp ở những người sống ở vùng cao (so với mặt nước biển), liên quan đến tình trạng thiếu oxy mạn tính [6],[8]. Yếu tố gia đình cũng được ghi nhận đặc biệt ở nhóm khối u cuộn cảnh hai bên [6]. Nghiên cứu của chúng tôi chưa đưa ra được các yếu tố về địa dư liên quan và không phát hiện bất kỳ bằng chứng về nguồn gốc gia đình có liên quan.

\subsection{Chẩn đoán}

5.2.1.U cuộn cảnh vùng cổ

*Lâm sàng: Đa số $\mathrm{BN}$ u cuộn cảnh vùng cổ đi khám với triệu chứng có khối vùng cổ/ góc hàm (bảng 1) thường phát triển chậm, không đau, không 
nóng đỏ, mật độ chắc, di động kém, không có tiếng thổi phù hợp với nhiều nghiên cứu $[1], 4,[9]$. Do vậy những $\mathrm{BN}$ đến khám với lý do có khối ở vùng cổ/ góc hàm cần nghĩ đến chẩn đoán phân biệt với $\mathrm{u}$ cuộn cảnh. Có tới $6 \mathrm{BN}$ ( 33,3\%- bảng 1$)$ đã được mổ ở tuyến trước, đều không có giấy tờ, $\mathrm{BN}$ mô tả nhớ lại chẩn đoán là hạch, hay u máu, hay u tuyến dưới hàm và đều không có kết quả GPB. Đây là một điểm cần rút kinh nghiệm để hạn chế chẩn đoán nhầm hay phát hiện bệnh muộn.

\section{*Cân lâm sàng.}

-Siều âm Doppler điển hình là khối giảm âm ở chỗ chia hai động mạch cảnh, khối u tăng sinh mạch. Đánh giá tình trạng xâm lấn, đè ép vào các động mạch cảnh, sự lưu thông các mạch này [10]. $100 \%$ BN của chúng tôi đều được làm thăm dò này (bảng 2), thậm chí làm nhiều lần.

- CLVT và CLVT đa dãy MSCT có bơm thuốc cản quang: cho chẩn đoán xác định u tiểu thể cảnh, chẩn đoán phân biệt, đồng thời đánh giá tình trạng động mạch cảnh ngoài và trong sọ. Trên phim thấy khối u thường hình bầu dục nằm ở vị trí chạc ba động mạch cảnh, làm roãng rộng hai động mạch cảnh, u bắt thuốc mạnh. U tiểu thể thần kinh phế vị nằm phía ngoài ĐM cảnh trong và $Đ M$ cảnh ngoài, nằm ở khoang cạnh hầu. $8 / 11$ BN $(72,7 \%)$ trên chụp MSCT có hình ảnh khối u tăng sinh mạch; và $9 / 11 \mathrm{BN}(81,8 \%)$ có hình ảnh đẩy roãng rộng chạc ba ĐM cảnh. Đây là phương tiện chẩn đoán tốt, ít xâm lấn và đã được tiến hành ở nhiều cơ sở y tế tại việt Nam, nhưng CLVT chỉ để chẩn đoán không có khả năng can thiệp hỗ trợ điều trị như chụp ĐM (nút mạch) [4], [5].

- Chụp mạch cảnh theo phương pháp Seldinger: $13 / 13 \mathrm{BN}(100 \%)$ có hình ảnh khối u tăng sinh mạch và $11 / 13 \mathrm{BN}(84,6 \%)$ có hình ảnh đẩy roãng rộng chạc ba ĐM cảnh. Đây là thăm dò góp phần chẩn đoán, đồng thời can thiệp nút mạch. Cả 13 BN chụp mạch với 14 khối u cuộn cảnh của chúng tôi đều được can thiệp nút mạch ngay (bảng 3 ). Thời điểm nút mạch lựa chọn là $24 \mathrm{~h}$ trước phẫu thuật theo khuyến cáo của UCSF (1996), làm hạn chế chảy máu, mất máu trong phẫu thuật, giảm tối đa nguy cơ tái tưới máu u bởi các nhánh phụ [7], [9]. Với những $\mathrm{BN}$ không có khả năng cắt $u$ (chông chỉ định gây mê, nhiễm trùng vùng cổ, kỳ vọng sống thấp...) thì nút mạch còn được coi là một giải pháp điều trị tạm thời giúp làm chậm sự phát triển của $u$.
- MRI: cung cấp chính xác cho phẫu thuật viên hình ảnh của khối u, mức độ xâm lấn, liên quan của khối u với bó mạch cảnh, các thành phần mô mềm lân cận và giúp phân loại giai đoạn khối u trước mổ [9],[10].

- PET-CT: chỉ định trong trường hợp nghi ngờ u cuộn cảnh ác tính (có di căn xa).

- Định lượng Catecholamine: Do u tiểu thể cảnh có bản chất là u cận hạch nên một số tác giả nghiên cứu định lượng catecholamine nhận thấy chỉ số này tăng cao trong máu và nước tiểu, đặc biệt ở những bệnh nhân có khối u với tính chất gia đình [5]. Bệnh nhân của chúng tôi chưa làm được xét nghiệm này.

- Mô bệnh học: giúp chẩn đoán xác định thể bệnh, định hướng theo dõi BN sau mổ, quyết định điều trị hỗ trợ sau mổ như tia xạ, hóa chất (với u ác tính, u có nguồn gốc thần kinh schwannoma) [9].

\subsubsection{U cuộn cảnh vùng thái dương}

*Lâm sàng: triệu chứng chủ yếu là ù tai theo nhịp mạch (tăng lên khi gắng sức, giảm đi khi đè mạnh vào vùng máng cảnh) $(5 / 5 \mathrm{BN})$ và nghe kém $(2 / 5 \mathrm{BN})$. Các triệu chứng về thần kinh như: liệt mặt một bên, nói khàn, nói khó, sụp mi...khi khối u lan rộng. Thực thể: nội soi thấy hình ảnh màng nhĩ sung huyết (hồng nhạt) góc trước dưới hoặc thấy u lan ra ống tai ngoài.

*Cận lâm sàng: Chủ yếu dựa vào chẩn đoán hình ảnh giống u cuộn cảnh vùng cổ ngoài ra có các chú ý sau:

- CLVT xương thái dương giúp xác định vị trí khối u, có hay không xương phần thấp của tai giữa liên quan với hành cảnh. Nếu có xương riêng biệt bao phủ hành cảnh và tách rời khối u khỏi động mạch cảnh thì phẫu thuật sẽ giới hạn ở tai giữa mà không liên quan đến mạch máu ở cổ. Hình ảnh điển hình là "muối tiêu".

- Sinh thiết: phân loại u cuộn cảnh với các u khác như u mạch máu, u nội mạc, saccome mạch máu, ung thư tai.Trong khi làm sinh thiết phải hết sức cẩn thận vì u này chảy máu rất nhiều. Chúng ta nên làm sinh thiết trong phòng mổ, có đủ dụng cụ để cầm máu, và phải chuẩn bị như là một phẫu thuật. Chúng ta dùng thòng lọng cắt khối u trong ống tai rồi nhét bấc thật chặt vào ống tai. Đối với khối u không xuất ngoại ra ống tai, ít khi chúng ta chẩn đoán đúng bệnh trước khi mổ và sinh thiết cũng chỉ có thể thực hiện sau khi đã mở xương chũm. 
- Các thăm dò khác: thính lực, nhĩ lượng...

-Giải phẫu bệnh: kết quả glomus tumor. Theo Gombos đa số u là lành tính, và được chữa khỏi bằng cách cắt bỏ toàn bộ u, nguy cơ $10 \%$ tái phát tại chố, khoảng $1 \%$ các khối u glomus được báo cáo là ác tính [11].

\section{3. Đối chiếu chẩn đoán hình ảnh với tổn thương trong mổ để rút ra kinh nghiệm cho chẩn đoán và chỉ định điều trị}

5.3.1.U cuôn cảnh vùng cồ

- Siêu âm Doppler: độ nhậy 78,9\% (15/19 u chẩn đoán chính xác-bảng 5).

- CLVT/ MSCT/ MRI: độ nhậy 88,9\% (16/18 u chẩn đoán chính xác-bảng 6 ).

Như vậy không có phương pháp chẩn đoán hình ảnh nào có giá trị chẩn đoán tuyệt đối, cần phối hợp để chẩn đoán chính xác.

5.3.2. U cuộn cảnh thái dương: BN không có tiền sử bệnh lý tai có ù tai theo mạch đập, nghe kém, CLVT có khối mờ trong hòm nhĩ, có thể có hình ảnh muối tiêu cần nghĩ tới u cuộn cảnh.

\subsubsection{Kết quả phẫu thuật}

-Phẫu thuật là biện pháp điều trị triệt căn duy nhất và có thể lấy được bệnh phẩm làm GPB (trong nghiên cứu của chúng tôi $100 \% \mathrm{BN}$ được mổ lấy toàn bộ khối $\mathrm{u}-$ bảng 4$)$. U cuộn cảnh dù bản chất tế bào là lành tính nhưng lại tiến triển theo kiểu ác tính (tỷ lệ ác tính từ $5-30 \%$, chèn ép hay xâm lấn tổ chức xung quanh) nên chỉ định phẫu thuật là bắt buộc [11],[12]. Tuy vậy cũng có những biến chứng nhất định sau mổ (Siêu âm tắc ĐM cảnh ngoài có $3 / 18(16,7 \%)$; khàn tiếng, nói khó $4 / 18(22,2 \%)$; rối loạn nuốt (phải mở thông dạ dày) $1 / 18(5,6 \%)$; Sụp mi (có hồi phục) 1/18 (5,6\%)). Qua nghiên cứu biến chứng sau mổ chúng tôi thấy rằng: chỉ nên tiến hành loại phẫu thuật này tại cơ sở chuyên khoa với phẫu thuật viên có kinh nghiệm, nơi có khả năng xử lý các loại thương tổn trong trường hợp $\mathrm{u}$ xâm lấn mạch máu. Ngoài phẫu thuật cần xem xét các phương pháp điều trị khác như xạ trị, nút mạch nhằm lựa chọn hướng giải quyết hợp lý nhất cho mỗi ca bệnh cụ thể, cũng như cần theo dõi, hướng dự phòng, phục hồi chức năng cho bệnh nhân sau phẫu thuật.

\section{KẾT LUẬN:}

U cuộn cảnh vùng đầu cổ là bệnh hiếm gặp (trong 9 năm chúng tôi chỉ gặp $23 \mathrm{BN}$ với $24 \mathrm{u}$ cuộn cảnh đủ điều kiện nghiên cứu). Trong đó, $\mathrm{u}$ tiểu thể cảnh hay gặp nhất $(70,8 \%)$. Triệu chứng lâm sàng không điển hình nhưng chẩn đoán được bằng siêu âm Doppler, chụp cắt lớp vi tính đa dãy và chụp mạch...Phẫu thuật cắt u là phương pháp lựa chọn chủ yếu. Ngoài ra cần xem xét các phương pháp điều trị khác như xạ trị, nút mạch, phẫu thuật bằng dao gamma nhằm chọn hướng giải quyết hợp lý nhất cho mỗi ca bệnh cụ thể.

\section{TÀI LIÊU THAM KHẢO}

1. Pellitteri P.K., Rinaldo A., Myssiorek D. et al (2004), Paragangliomas of the head and neck, Oral oncology, Vol 40, pp. 563-567.

2. Luna-Ortiz K., Rascon-Ortiz M., Villavicencio-Valencia V. et al (2005), Carotid body tumors: review of a 20-year experience, Oral Oncol, Vol 41(1), pp. 56-61.

3. Maison Casarim A.L., Tincani A.J., Negro A.D. et al (2014), Carotid body tumor: Retrospective analysis on 22 patients, Sao Paulo Med J, Vol 132(3), pp. 133-9.

4. Đoàn Quốc Hưng (2015), U tiểu thể cảnh: Một số kinh nghiệm trong chẩn đoán và điều trị. Tap chí Tai mũi hong, 6: 51-60.

5. Đoàn Quốc Hưng, Nguyễn Duy Thắng, Lê Thanh Dũng, Mai Thanh Tú (2011), U tiêu thể cảnh: chẩn đoán và điều trị tại bệnh viện Hữu nghị Việt Đức, Tạp chí tim mạch học Việt Nam, Vol 59, pp. 46-53.

6. Shedd D.P. (1990), Familial occurrence of carotid body tumors, Head and Neck, 12(6).

7. Durdik S., Malinovsky P., Durdik S. P Malinovsky (2002), Chemodectoma-carotid body tumor surgical treatment, pp. 422-423.

8. Chao C., Perez C., Brady L. (2011), Unusual tumors of the head and neck. Radiation oncology management decisions, 3rd edition. Philadelphia, Lippincott, pp. 299-302.

9. Rodriguez-Cuevas H., Lau I., Rodriguez H.P. (1986), High-altitude paragangliomas: diagnostic and therapeutic considerations, Cancer, Vol 57(3), pp. 672-6.

10. Urquhart A.C., Johnson J.T., Myers E.N., (1994), Glomus vagale: paraganglioma of the vagus nerve, Laryngoscope, vol 104, pp. 440-445.

11. Gattuso, Reddy, David (2002), Defferential Diagnosis in Surgical Pathology $2^{\text {nd }}$, Sunder Elsevier.

Gombos Z., Zhang P.J. (September 2008), Glomus tumor, Archives of pathology \& laboratory medicine, Vol 132 (9), pp. 1448-52. 